\title{
An uncommon pattern of oesophageal cancer presentation
}

\author{
Aderemi Oluyemi ${ }^{1}$, Adekunle Adeyomoye ${ }^{2}$ \\ 1. ReMay Consultancy \& Medical Services, Opebi, Lagos State, Nigeria. 2. Lagos University Teaching Hospital, Idi-Araba, \\ Lagos State, Nigeria
}

Correspondence: Aderemi Oluyemi, Consultant Gastroenterologist. Address: ReMay Consultancy \& Medical Services, Opebi, Lagos State, Nigeria. Email: remioluyemi@yahoo.com

Received: September 29, 2014

Accepted: November 24, 2014

DOI : $10.5430 /$ crim.v2n3p77

URL: http://dx.doi.org/10.5430/crim.v2n3p77

Online Published: August 2, 2015

\section{Abstract}

Introduction: Common morphological patterns of oesophageal cancer presentation include stricture formation, mucosal ulceration, or the presence of exophytic fungating masses, nodules, and fistulae. The varicoid type is, however, rare.

Case presentation: The index case is a 74-year-old lady who had no classical complaints that are often associated with oesophageal cancer and had the varicoid type discovered on endoscopy screening.

Conclusion: The purpose of this case report is to document such a pattern for the first time in the authors' environment and to highlight the utility of endoscopy in early detection of malignancy when commonly identified signs and symptoms are absent.

\section{Keywords}

Varicoid, Oesophageal carcinoma, Endoscopy

\section{Introduction}

In the literature, the morphological descriptions of the reported cases of carcinomas of the oesophagus are diverse and include terms such as fungating, ulcerating, and lumen-occluding. However, an uncommon type of presentation, the varicoid variant of oesophageal carcinoma, was present in this case report of a 74-year-old female who presented with early signs and symptoms that appeared unrelated to malignancy. The term "varicoid" is defined as a swelling that resembles a varix, or an enlarged and convoluted vessel.

\section{Case presentation}

We report a case of a 74-year-old female with no significant past medical history who initially presented with complaints of epigastric abdominal pain and diminished energy of two weeks' duration. The pain was present most times of the day, did not radiate elsewhere, and exhibited no relationship to meals or particular foods. She had not noticed any dysphagia or odynophagia, and she denied any weight loss. There was no history suggestive of liver disease. 
Physical examination revealed palmar erythema without evidence of a thyroid swelling. Examination of the abdomen and other systems was unremarkable. An immediate endoscopy was performed on account of late onset dyspepsia.

Endoscopic findings consisted of a mid-oesophageal varicoid lesion with longitudinally-oriented swelling, distinct ridges, nodular surface, and an infiltrative appearance (see Figure 1). In contrast to true varices, this lesion appeared white and pallid, and it did not change in colour or caliber with changes in the patient's respiration or position. Although the lesion protruded into the oesophageal lumen, there was no evidence of significant compromise of the intra luminal caliber. The mass did not involve the oesophagogastric junction. Samples were taken from the lesion for histopathologic assessment.

Figure 1. Image from oesophagoscopy showing the multiple solid white and pallid nodular lesions with an infiltrative pattern in the mid oesophageal region

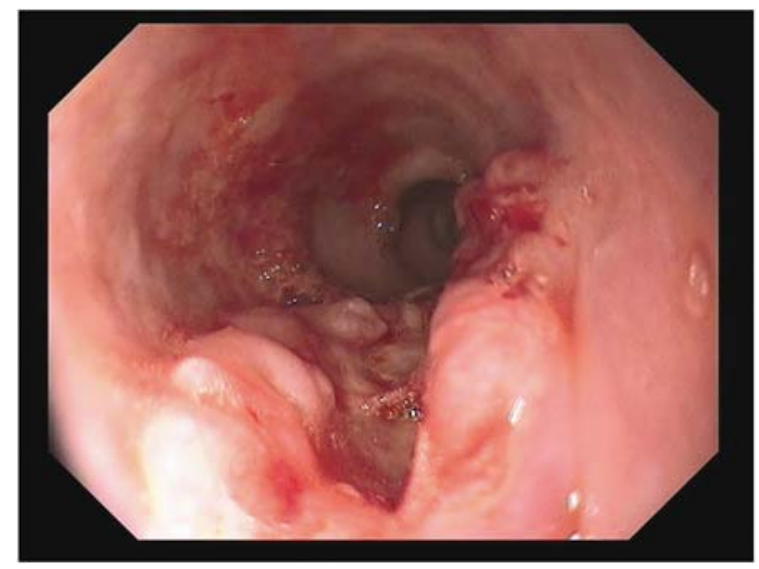

Subsequently, a computed tomographic (CT) scan (see Figure 2) revealed an asymmetric, irregularly thickened cauliflower mass in the upper, anterior oesophageal wall. There was no evidence suggestive of regional lymphadenopathy. The oesophagus-trachea fat plane was well-preserved and there was no evidence of stranding of the mediastinal fat.

Histopathologically, the lesion was diagnosed as an infiltrating, low-grade squamous carcinoma. A surgical oncology consultation was advised and the patient is currently receiving appropriate treatment.

Figure 2. Contrast enhanced computed tomographic scan of the chest at the level of the superior mediastinum showing an asymmetric, irregularly thickened mass in the anterior oesophagealwall (arrow). Note the preservation of the fat plane with the trachea and lack of stranding of the mediastinal fat. No regional adenopathy was identified

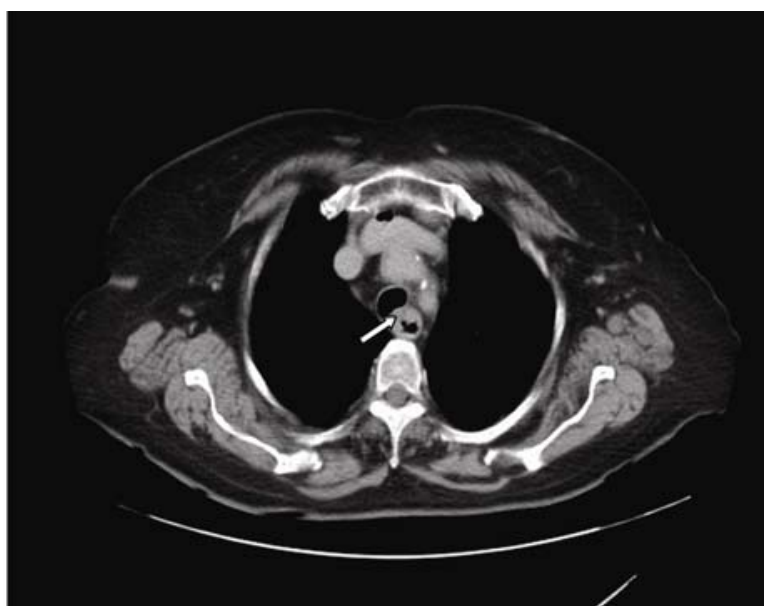

\section{Discussion}

The varicoid pattern of presentation of oesophageal cancer is uncommon. In fact, this is the first time, to the best of the authors' knowledge, that such a case has been documented in our region. The term is defined as a swelling that resembles a varix, or an enlarged and convoluted vessel. Histopathologically, it is used to denote an oesophageal carcinoma which is 
usually of the squamous type and demonstrates an uncommon pattern of dissemination via the vasculature and the lymphatic system of the submucosa ${ }^{[1]}$.

At initial presentation, the two most common symptoms of oesophageal cancer in our region are dysphagia and progressive weight loss, as reported in many other parts of the world ${ }^{[2,3]}$. Dysphagia usually results from advanced lesions that have led to substantial compromise in the caliber of the oesophageal lumen ${ }^{[3,4]}$. The oesophagus is not lined by a serosal layer, which allows the smooth muscles of other gastrointestinal components to stretch. As a result, dysphagia may not set in until the lumen is more than $50 \%-60 \%$ obstructed by the tumor ${ }^{[4]}$. This, in part, explains why the prognosis is dismal for many patients with oesophageal cancer.

An interesting clinical feature of this particular type of oesophageal cancer is that dysphagia has been noted not to be as common a presenting complaint as it is in other patterns of cancer presentation in the oesophagus ${ }^{[5]}$. The index case, here presented, illustrates this useful clinical difference. Another feature that is worthy of note in differentiating these lesions is the presence or otherwise of history or physical examination findings that are suggestive of chronic liver disease (CLD). This is important as it has been noted that background CLD with portal hypertension is the commonest cause of oesophageal varices ${ }^{[6]}$. Hence, certain authors have opined that the appearance of varicoid lesions in the oesophagus in the absence of CLD should be regarded with a high index of suspicion for possible varicoid esophageal cancer ${ }^{[7]}$.

The two lesions, on endoscopy share certain similarities in that they both appear commonly as multiple lesions whose orientation is along the oesophageal longitudinal axis. But they have can be differentiated by the fact that at oesophagoscopy, a true varix will typical have a bluish and soft character while varicoid variant of oesophageal carcinoma appears as a solid, nodular, white or pallid lesion usually present in either the middle or lower segments ${ }^{[5,8]}$. Radiologically, the two differential lesions both show the typical irregular oesophageal filling defects on barium oesophagogram but can be distinguished after careful consideration because oesophageal varices can be effaced by distension of the oesophagus during double contrast oesophagram ${ }^{[7]}$. Also to be noted is the fact that oesophageal varices are flexible, and their size alters with changes in the patients' respiration and position ${ }^{[1]}$. These latter characteristics (effacement with oesophageal distension, flexibility with size alterations in response to respiration and position) are typically absent in the more rigid though equally serpentine-appearing varicoid oesophageal cancer.

Ultimately though, a biopsy is required for histopathologic diagnosis, as there have been reports of confusion between these two lesions ${ }^{[9]}$.

The histology of biopsies from the case report revealed low grade squamous carcinoma. This report is in keeping with the most of surveys conducted on patients with oesophageal cancers in our region and beyond ${ }^{[2,3]}$. The vast majority of reports

of similar varicoid lesions also are of the squamous type ${ }^{[1,5,7]}$. However, two cases of varicoid oesophegal cancers have been documented to be adenocarcinomas ${ }^{[5,7]}$.

\section{Conclusion}

In this described case, we wished to highlight the rarity of this morphological pattern of presentation of oesophageal cancer particularly from the African sub-Saharan region.

The onus is therefore on the clinicians to have a high index of suspicion and utilize endoscopy to rule out or rule in these lesions at an early stage. This is, however, easier said than carried out in resource-limited settings in light of the many challenges associated with endoscopy practice ${ }^{[2]}$, but it is certainly not impossible, as this case report opines. 


\section{References}

[1] Sabedotti G, Dreweck MO, Sabedotti V, et al. Carcinoma of the Esophagus: Varicoid Pattern. RadioGraphics. 2006; $26: 271-274$. PMid:16418257 http://dx.doi.org/10.1148/rg.261045209

[2] Abdulkareem FB, Onyekwere CA, Awolola NA, et al. A clinicopathologic review of oesophageal carcinoma in Lagos. Nig Qt J Hosp Med. 2008; 18(2): 53-56. PMid:19068551

[3] Schlansky B, DimarinoJr AJ, Loren D, et al. A survey of oesophageal cancer: pathology, stage and clinical presentation. Alimen Pharmacol Ther. 2006; 23: 587-593. PMid:16480397 http://dx.doi.org/10.1111/j.1365-2036.2006.02782.x

[4] Tettey M, Edwin F, Aniteye E, et al. The changing epidemiology of esophageal cancer in sub-Saharan Africa-the case of Ghana. Pan Afr Med J. 2012; 13: 6-12. PMid:23308313

[5] Odes HS, Maor E, Barki Y, et al. Varicoid carcinoma of the esophagus: report of a patient with adenocarcinoma and review of literature. Am J Gastroenterol. 1980; 73: 141-145. PMid:7053196

[6] Agha FP. Solitary Esophageal Varix Simulating a Neoplasm. Australas Radio. 1988; 32: 487-489. http://dx.doi.org/10.1111/j.1440-1673.1988.tb02785.x

[7] Kant P, Sahay P. Varicoid adenocarcinoma of the esophagus: case report. Dysphagia. 2008; 23(2): 205-7. PMid:18058174 http://dx.doi.org/10.1007/s00455-007-9129-9

[8] Itoh H, Ohtani H, Kataoka M, et al. Carcinoma ofthe esophagus simulating “downhill” varices. Radiat Med. 1987 ; 5(3): 83-85. PMid:3423295

[9] Lawson TL, Dodds WJ, Sheft DJ. Carcinoma of the esophagus simulating varices. Am J Roentgen. 1969; 107 : 83-85. PMid:5811570 http://dx.doi.org/10.2214/ajr.107.1.83 